\title{
EXPANSÃO NO SISTEMA DE CONCESSIVIDADE: A GRAMATICAlizAÇÃo DE APESAR DE (QUE) NA HISTÓRIA DO PORTUGUÊS
}

\author{
EXPANSION OF THE CONCESSIVE SYSTEM: THE GRAMMATICALIZATION \\ OF APESAR DE (QUE) IN THE HISTORY OF PORTUGUESE
}

\author{
Sanderléia Roberta Longhin | Lattes | sanderleia.longhin@unesp.br \\ Universidade Estadual Paulista | CNPq
}

\begin{abstract}
Resumo: Este artigo trata do processo de gramaticalização do qual resultou a perífrase concessiva apesar de (que) na história em português. Com base no caráter fundante de mecanismos cognitivos e pragmáticos, no impacto dos contextos de uso e em um protótipo de juntor concessivo, busco responder às questões: que traços do nome pesar, aliados a contextos particulares, ajudam a explicar a predisposição à mudança? como as relações concessivas expressas por apesar de (que) refletem fatos de seu percurso de constituição? que relações podem ser apreendidas entre a implementação gradual da mudança de significado e a composição estrutural como juntor complexo? A pesquisa é conduzida à luz de uma metodologia diacrônica pautada nos padrões polissêmicos de pesar, com suas respectivas propriedades distribucionais. Os resultados fornecem um mapa cronológico detalhado de possíveis estágios de mudança, nos quais sobressaem o peso da fonte pesar, enquanto shell noun, para as generalizações sintática e semântica e para a ação dos processos inferenciais que habilitaram as relações concessivas dos tipos causa negada e restritiva.
\end{abstract}

Palavras-chave: Gramaticalização. Junção. Diacronia. Concessão.

Abstract: This paper discusses the grammaticalization process that generated the concessive periphrasis apesar de (que) in the history of Portuguese. Based on the founding nature of cognitive and pragmatic mechanisms, on the impact of contexts of use, and on a prototype of a concessive marker, our goal is to answer the following questions: which features of the noun pesar, combined with specific contexts, do help us explain the predisposition to this change? In which way do the concessive relations conveyed by apesar de (que) reflect facts of its constitution journey? Which relations may be apprehended with the gradual implementation of semantic change, and the structural composition as a complex junctive word? The research is carried out regarding the diachronic methodo- 
logy ruled by polysemic patterns of pesar, with its respective distributive properties. The results provide a detailed chronological map of possible stages of change, in which the weight of the source word pesar, as a shell noun, is highlighted for syntactic and semantic generalizations and also for the action of the inferential processes that allowed concessive relations of cause denied and restrictive.

Keywords: Grammaticalization. Junction. Diachrony. Concession.

\section{Introdução}

O sistema de concessão do português não mostra herança do quadro conjuncional latino e os mecanismos de junção concessiva hoje disponíveis, tipicamente frasais como, por exemplo, ainda que, mesmo que, se bem que, a pesar de (que), sem que, etc., resultaram da reinterpretação de material do próprio repertório da língua, em desenvolvimentos históricos até certo ponto previsíveis a partir da relativa transparência das fontes e da afinidade entre concessividade e outros domínios semânticos. Em perspectiva translinguística, no conjunto das fontes mais produtivas para a criação de juntores ${ }^{1}$ concessivos estão palavras e construções que expressam sentimentos humanos (KÖNIG, 1985; HARRIS, 1988), de que o nome pesar, do português, é uma instância. Neste trabalho, investigo, em viés diacrônico, o processo de gramaticalização que levou o nome pesar a ser reinterpretado, em contextos específicos, como juntor complexo, apesar de e apesar de que, que expressa relações concessivas, como em $(1)$ a $(3)^{2}$, dados extraídos do corpus desta pesquisa.

(1) Apesar da idade, ainda usava chupeta. (20AVE)

(2) (...) fomos subindo, a 7 mil, na velocidade de um avião próprio para tais alturas. Apesar de levarmos todos máscara de oxigênio o coração baqueou e cheguei até a ter hemorragia nasal (20CFF)

(3) Os aromáticos são empregados a vontade, apesar de que não contribuem de modo algum para a conservação d'este alimento. (20CDC)

Esses dados mostram que as construções com pesar podem se realizar em esquemas sintáticos diferentes: em (1), apesar de seleciona um nome; nos demais, seleciona ora-

\footnotetext{
${ }^{1}$ Utilizo juntor como termo genérico para referir a vários mecanismos de conexão que incluem conjunção, preposição, perífrase conjuncional, perífrase preposicional e expressão adverbial juntiva.

2 As siglas, no final dos exemplos, indicam a procedência do dado: o número indica o século e as letras, as iniciais do texto. A relação completa dos textos com as respectivas siglas é apresentada no Quadro 1, Seção 2.
} 
ções, não finita e finita, respectivamente. A ordem das orações é variável e se correlaciona com manobras concessivas distintas. Compare (1) e (2), concessivas antepostas, cujo significado se baseia em uma pressuposição de causalidade; e (3), posposta, cujo significado se baseia em um procedimento de restrição.

Filiando-me a um quadro teórico pautado no caráter fundante dos mecanismos cognitivos e pragmáticos e no impacto dos contextos de uso (TRAUGOTT; DASHER, 2002; HEINE; KUTEVA, 2007; BYBEE, 2010³), o objetivo maior deste artigo é alcançar uma explicação sobre as condições em que se processaram as alterações categorial e semântica, buscando responder às questões: que traços do nome pesar, aliados aos contextos de uso, ajudam a explicar a predisposição à mudança? como as nuanças concessivas específicas das construções com pesar refletem fatos de seu percurso de constituição? que relações podem ser apreendidas entre a implementação gradual da mudança de significado e a composição estrutural como juntor complexo? Os padrões polissêmicos com suas respectivas propriedades distribucionais constituem o eixo metodológico norteador que, juntamente com um protótipo de juntor concessivo, permitirão investigar, em perspectiva longitudinal, o processo gradual de consolidação dos traços de forma e de significado que estão em jogo para a constituição da nova construção ${ }^{4}$.

Organizo o artigo em três seções, excetuando-se esta Introdução e as Considerações Finais. Na primeira seção, apresento os subsídios teóricos e reúno propriedades que possibilitam delinear um protótipo de juntor concessivo. Na segunda, descrevo os critérios utilizados para seleção da amostra e recorte do corpus e exponho as decisões tomadas para a operacionalização metodológica, tendo em vista as questões de pesquisa. Na terceira seção, compartimentada em duas subseções, apresento a análise dos dados e a interpretação dos resultados.

\section{Quadro teórico}

Este trabalho é desenvolvido sob os pressupostos teórico-metodológicos da gramaticalização, nos moldes de Traugott e Dasher (2002), Heine e Kuteva (2007) e Bybee (2010), que fornecem subsídios para descrição de processos de mudança - graduais e

\footnotetext{
${ }^{3}$ Trabalhos similares, nessa perspectiva teórica, foram realizados acerca de in spite of, do inglês (BYBEE, 2010), e de a pesar de, do espanhol (TORRES CACOULLOS; SCHWENTER, 2005; TORRES CACOULLOS, 2006). A trajetória de mudança de apesar de (que), do português, tal como descrita neste trabalho, mostra regularidades com aquelas do inglês e do espanhol, reforçando tendências filogenéticas no âmbito da junção concessiva.

${ }^{4}$ Utilizo construção para me referir ao próprio juntor, que é fruto da reanálise de uma sequência de palavras, como também para me referir ao esquema de junção de que o juntor participa e do qual resulta a expressão de concessão. Nesses termos, a construção é a unidade de análise.
} 
relativamente regulares - que resultam em construções mais gramaticais, mais abstratas e mais subjetivas. Os processos de gramaticalização constituem evidências de que os sistemas linguísticos são produtos emergentes cujas motivações repousam nas condições de uso e no processamento cognitivo.

Em gramaticalização, o conceito de chunking, refinado em Bybee (2010), é especialmente importante para explicar a formação de unidades frasais, como as perífrases com pesar. Entende-se por chunk uma sequência de palavras que, usada em dado contexto, desenvolve relações e passa a ser processada e enunciada como um bloco coeso. A exposição dessas sequências à repetição favorece a perda de transparência dos seus componentes, nos níveis morfossintático e semântico, e confere aos chunks graus crescentes de convencionalização. Associadas à noção de chunk estão, portanto, as medidas de composicionalidade e analisabilidade. A composicionalidade é semântica, refere-se ao grau de previsibilidade do significado da construção a partir do significado de suas partes, a analisabilidade é morfossintática, refere-se ao grau de reconhecimento das partes componentes, morfemas e palavras, e à contribuição de cada uma para a construção. Com o avanço da mudança, o que se espera observar é a perda gradual de traços de analisabilidade e de composicionalidade, tão fundamental para a formação da nova construção (BYBEE, 2010).

A mudança de significado que acompanha a gramaticalização tem duas faces e ambas estarão em pauta. Há, por um lado, uma tendência ao enfraquecimento ou generalização do significado fonte, mecanismo que possibilita a expansão e a adequação da construção a novos contextos. Por outro, há ganhos oriundos de enriquecimentos inferenciais, que dependem de uma convergência entre informações contextuais e estruturas conceituais partilhadas. As estruturas conceituais, cruciais para o mecanismo inferencial, são parte de representações mentais continuamente ampliadas pelas tantas experiências dos usuários com a língua. Algumas inferências ganham força, em determinados contextos, a ponto de tornarem-se parte do significado da construção.

Há evidências em inúmeras línguas de que a mudança de significado tem uma direção previsível rumo ao aumento de subjetividade. Em diacronia, a subjetivização consiste em um processo semasiológico, de natureza gradiente, pelo qual, no curso do tempo, o usuário desenvolve significados capazes de expressar suas perspectivas ou atitudes a respeito do conteúdo das proposições, das posições argumentativas e do próprio evento comunicativo (TRAUGOTT; DASHER, 2002). 
As relações concessivas são altamente subjetivas, compreendem "one of the most interesting achievements of human intellect" (RUDOLPH, 1996, p. 385). São utilizadas para enfatizar que os eventos colocados em combinação contradizem as expectativas, considerando as experiências e o conhecimento de mundo. Realizam-se em construções binárias do tipo embora $p$, $q$, em que $p$ e $q$ são estados de coisas afirmados no contexto de uma suposição relativa à incompatibilidade geral de tais situações. $\mathrm{O}$ padrão de implicação é normalmente se p, então não-q (KÖNIG, 1985; RUDOLPH, 1996; KORTMANN, 1997; entre outros), no qual intervém os conceitos de causalidade e de negação.

\subsection{Um protótipo de juntor concessivo}

O trânsito de nome a juntor complexo é um caminho previsível para ampliação de paradigmas conjuncionais nas línguas (PAUL, 1886; KORTMANN, 1997; HAGÈGE, 2001). Esse trânsito implica obviamente perdas e ganhos de propriedades formais e semânticas. Para a análise dos ganhos, busco um protótipo de juntor concessivo, para que do reconhecimento das propriedades típicas seja possível extrair uma espécie de roteiro metodológico a ser percorrido na análise das construções em mudança, nos vários estados de língua.

Algumas dessas propriedades são equacionadas em Kortmann (1997). O autor elenca propriedades gerais típicas de conectores que realizam subordinação adverbial e/ ou de construções de que eles participam: são formas não passíveis de flexão; operam sobre uma estrutura em sujeito e predicado não necessariamente finita; não exercem função sintática dentro da oração que encabeçam e assumem posição fixa na margem da oração. Para conectores perifrásticos, incluindo os de base nominal, foco deste trabalho, Kortmann afirma que o pertencimento à categoria depende da satisfação de pelo menos uma das três condições: os elementos da perífrase devem exibir uma fusão mínima; devem ter perdido algumas das propriedades do sintagma original; e a expressão deve ter um significado adverbial que não seja obtido do significado das partes. A aplicação dessas condições ao estudo da perífrase apesar de, como se verá, depende do refinamento dos parâmetros de aferição. As duas primeiras condições, de fundo morfossintático, estão ligadas às medidas de analisabilidade, enquanto a terceira, de fundo semântico, às medidas de composicionalidade.

Os juntores concessivos, como é peculiar à junção contrastiva, têm dois componentes: o conceitual, codificado semanticamente, que ativa conhecimentos e representa- 
ções de mundo; e o procedural, que estabelece restrições sobre a interpretação, com forte apelo contextual, levando a conclusões que não poderiam ser obtidas em sua ausência (MOESCHLER, 2002). Nesses termos, a concessão é "un acte de nature argumentative et interactive" (LETOUBLON, 1983, p. 86). Seus processos históricos de constituição envolvem uma fronteira entre a codificação semântica e inferenciação pragmática, que vai se mostrando dinâmica no tempo, ora com prevalência da inferenciação, ora da codificação (PRANDI, 2004; MAURI; AUWERA, 2012). Essa dinâmica é apreensível diacronicamente, em construções subcodificadas que experimentam codificação crescente, com redução gradual da inferência, promovendo alteração de padrões.

Assumo que, na articulação de orações, a expressão dos significados depende: i) do significado das partes, ii) do significado do juntor e iii) da interpretação que resulta da aplicação de i) e ii) no contexto (estrutural, discursivo e conhecimento de mundo). No caso das relações concessivas, a expectativa é a de que as partes articuladas devem impor restrições para interpretação e que o juntor forneça as instruções sobre como interpretar a relação entre essas partes. Nessas instruções está uma suposição de incompatibilidade, induzida contextualmente (MOESCHLER; SPENGLER, 1982; LANG, 2000; MOESCHLER, 2002, entre outros), que é fruto da avaliação do falante ou escrevente, portanto, é um índice de subjetividade. Dessa maneira, processos de inferenciação pragmática sempre subjazem, em alguma medida, a construção do significado concessivo.

\section{Seleção da amostra, recorte do corpus e metodologia}

Em consonância com os objetivos propostos, a diacronia é a via metodológica que pode trazer luz sobre as conexões entre fonte e alvo e sobre os estágios graduais de desenvolvimento. $\mathrm{O}$ corpus diacrônico foi compilado a partir de um conjunto de textos de gêneros diversos, das variedades europeia e brasileira do português, extraídos de seis plataformas ${ }^{5}$. Para a constituição do corpus, estabeleci diretrizes relativas ao recorte temporal (séc. XIII ao XXI), à diversidade tipológica de sequências textuais (narrativas, argumentativas e prescritivas) e à quantidade de material similar para cada estado de língua, de modo a obter um material comparável quantitativa e qualitativamente. O Quadro 1, a seguir, relaciona os textos selecionados, nas duas metades de cada século, com suas respectivas siglas de referência utilizadas neste trabalho.

\footnotetext{
5 Tycho Brahe Parsed Corpus of Historical Portuguese; Corpus Informatizado do Português Medieval; Corpus de textos antigos; Projeto História do Português Brasileiro, Projeto História do Português Paulista e Acervo digital da Biblioteca Brasiliana.
} 
Quadro 1. Relação da amostra de textos para extração do corpus

\begin{tabular}{|c|c|}
\hline Período & Textos e siglas de referência \\
\hline Séc. XIII & $\begin{array}{l}\text { 1.METADE: Notícias de Torto (13NT); Cantigas de amigo (13CA); Testamento de } \\
\text { D. Afonso II (13TDA); Cantigas de amor (13CAM). } \\
\text { 2.METADE: Cantigas de Santa Maria (13CSM), Foro Real de Afonso X (13FRA), } \\
\text { Dos Costumes de Santarém (13DCS); Documentos Notariais (13DN), Tempo } \\
\text { dos Preitos (13TP), Chancelaria D Afonso III (13CDA). }\end{array}$ \\
\hline Séc. XIV & $\begin{array}{l}\text { 1.METADE: A arte de Trovar (14AT), Foros de Garvão (14FV), Dos Costumes de } \\
\text { Santarém (14DCS), Vidas de Santos (14VS), Narrativas de Linhagem (14NL), } \\
\text { Cantigas de amor (14CA), Textos Notariais (14TN), Chancelaria D. Afonso } \\
\text { (14CDA), Livro do Mártires (14LMT), Trasladação de S. Nicolau (14TSN). } \\
\text { 2.METADE: Crônica Geral de Espanha (14CGE), Livro da Montaria (14LM), Corte } \\
\text { Imperial (14CI), Primeira Partida - Alphonse X (14PP), Flos Sanctorum (14FS). }\end{array}$ \\
\hline Séc. XV & $\begin{array}{l}\text { 1.METADE: Orto do Esposo (15OE), Livro dos Ofícios (15LO), Demanda do Santo } \\
\text { Graal (15DSG), Livro da Ensinança de bem cavalgar (15LEC), Leal Conselheiro } \\
\text { (15LC), Crônica D. Pedro I (15CDP), Penitencial (15P), Livro do Regimento } \\
\text { Évora (15LRE). } \\
\text { 2.METADE: Tratado de Confissão (15TC), Carta de Caminha (15CC), Sacramental } \\
\text { (15S), Livro das três virtudes (15LTV), Crônica Del-Rei D. Dinis (15CDD), } \\
\text { Crônica D. Afonso (15CDA), Castelo Perigoso (15CP), Dia do Juízo (15DZ), } \\
\text { História de Vespasiano (15HNV). }\end{array}$ \\
\hline Séc. XVI & $\begin{array}{l}\text { 1.METADE: Regra de São Bento (16OSB); Crônica del-Rei D. Afonso Henriques } \\
\text { (16CAH); Cartas D. João III (16CDJ); Teatro Antonio Chiado (16TC); Livro das } \\
\text { constituições e costumes (16LCC); Gramática de João de Barros (16GJB); Regras } \\
\text { da ordem de Santiago (16OS); Da Pintura antiga (16DPA). } \\
\text { 2.METADE: Teatro Sá de Miranda (16TSM); Peregrinação (16P); Colóquios dos } \\
\text { simples e drogas (16CSD); Leis e provisões (16LP); Décadas (16D); História de } \\
\text { Santa Cruz (16HSC); Arte de grammatica da lingoa (16AG); Teatro de Gil Vicente } \\
(16 \mathrm{TGV).}\end{array}$ \\
\hline Séc. XVII & $\begin{array}{l}\text { 1.METADE: Trattado das festas evida dos santos (17TFV); Avida de Frei Bartolomeu } \\
\text { (17VFB); Discursos vários políticos (17DP); Jornada dos Vassalos da Coroa de } \\
\text { Portugal (17JVC); Da Monarchia Lusitana (17ML); Gazeta (17G); Chronica da } \\
\text { Companhia de Jesus (17CCJ); Corte na aldeia e noites de inverno (17CA). } \\
\text { 2.METADE: Cartas de Padre Vieira (17CPV); Relaçam diária do sitio (17RDS); } \\
\text { Cartas José Brochado (17CJB); Arte de furtar (17AF); O Fidalgo aprendiz } \\
\text { (17OFA); Diálogos de varia história (17DVH); Nova Lusitânia (17NL); Maria } \\
\text { Rosa Mística (17MRM). }\end{array}$ \\
\hline
\end{tabular}




\begin{tabular}{c|l}
\hline Séc. & $\begin{array}{l}\text { 1.METADE: Katecismo indico (18CI); Por rumos na agulha (18PRA); Cultura e } \\
\text { opulência (18CO); Auto novo e curioso (18AN); História das imagens milagrosas } \\
\text { (18HIM); Suplemento vocabulário português (18SVP); Carta de aldeamento de } \\
\text { índios (18CAI); História da América Portuguesa (18HAP). } \\
\text { 2.METADE: Reflexões sobre a vaidade (18RSV); O fazendeiro do Brazil (18OFB); } \\
\text { Caminhando mato dentro (18CMD); Dizertação Capitania de São Paulo (18DCS); } \\
\text { Breves instruções aos correspondentes (18BIC); Cartas Pina Manique (18CPM); } \\
\text { A vingança da cigana (18VG); Helmintologia portuguesa (18HP). }\end{array}$ \\
\hline Séc. XIX & $\begin{array}{l}\text { 1.METADE: Memória histórica e metallurgica (19MHM); Sangue limpo (19SL); } \\
\text { Anúncios de jornais brasileiros (19AJB); Cartas brasileiras (19CB); Cartas de } \\
\text { leitores (19CL); O cavalleiro teutônico (19CT); A estátua amazônica (19EA); } \\
\text { Tratado descritivo do Brazil (19TDB). } \\
\text { 2.METADE: Instituto dos meninos cegos (19IMC); História e descrição da febre } \\
\text { amarela (19DFA); Systema de matéria médica vegetal (19SMM); Phisiologia das } \\
\text { paixões (19FPA); Luxo e vaidade (19LV); Breves considerações sobre a história } \\
\text { (19BC); Do princípio e origem dos índios (19POI); Correspondência Washington } \\
\text { Luiz (19CWL). }\end{array}$ \\
\hline Séc. XX/ \\
XXI & $\begin{array}{l}\text { 1.METADE: Brasil Marcial (20BM); Correspondência Washington Luiz (20CWL); } \\
\text { O cozinheiro dos cozinheiros (20CDC); Almanach de Pernambuco (20AP); O rei } \\
\text { da vela (20ORV); Compêndio narrativo peregrino (20CNP); O café na história } \\
\text { (20OCH); História dos feitos no Brasil (20HFB). } \\
\text { 2.METADE: Correspondência Fidelino Figueiredo (20CFF); Açúcar fator de equilí- } \\
\text { brio (20AFE); Revista da Faculdade de Direito (20RFD); Reforma Fiscal (20RF); } \\
\text { A vida como ela é (20AVE); Roteiro de Zuzu Angel (21ZA); Língua falada em São } \\
\text { Paulo (21LPF); Inquéritos do Iboruna (21IB). }\end{array}$ \\
\hline
\end{tabular}

Fonte: Elaborado pela autora

Nas amostras dos séculos XIII ao XV, a busca pelas ocorrências se deu manualmente, por meio de ferramentas disponíveis para documentos nas extensões DOC e $\mathrm{PDF}^{6}$. Para as amostras dos demais séculos, utilizei a ferramenta computacional Sketch Engine, que permitiu compilar, controlar o número de palavras e selecionar as ocorrências em seus contextos de uso. Embora a Sketch tenha agilizado muito a etapa de preparação dos dados, mostrou alguma limitação no reconhecimento de dados de períodos pretéritos, sendo necessária uma checagem manual em cada texto.

Do ponto de vista metodológico, a polissemia é o parâmetro norteador das descrições e análises, conduzidas nos vieses qualitativo e quantitativo. No qualitativo, assumindo que as polissemias se relacionam a propriedades distribucionais distintas, busco uma descrição mais fina dos dados em termos das nuanças de significado, base para o reconhecimento dos padrões funcionais, aliada a uma descrição dos correlatos morfossintáticos de cada padrão, dentro de seus respectivos contextos de uso. À maneira de Mauri e Ramat (2012), adoto o parâmetro semântico como o mais geral e postulo três valores, 
que são aferidos longitudinalmente: compatibilidade somente com o significado fonte; dupla compatibilidade com os significados fonte e alvo; e compatibilidade somente com o significado alvo. Outros detalhes da operacionalização dos parâmetros são apresentados na seção de análise.

No viés quantitativo, apuro a frequência absoluta, obtida a partir da contagem geral dos dados de pesar e a frequência relativa, a partir da divisão entre a frequência absoluta de cada padrão funcional de pesar e o número total de observações do fenômeno. A frequência relativa, em especial, tem a vantagem de neutralizar possíveis discrepâncias relativas ao gênero dos textos que compõem a amostra e, da perspectiva da mudança, pode indicar grau de autonomia da nova construção, como resultado do enfraquecimento de traços de analisabilidade e composicionalidade (BYBEE, 2010).

\section{3. $O$ percurso de pesar rumo à expressão de concessão}

O mapeamento dos dados de pesar no corpus diacrônico resultou em 812 ocorrências $^{7}$, que se distribuem por cinco diferentes padrões funcionais. Dois deles são lexicais, em que pesar atua como nome e como verbo pleno, conforme (4) e (5), respectivamente. Os padrões gramaticais são frasais e participam de relações de concessividade: incluem as perífrases preposicional e conjuncional apesar de e apesar (de) que, e a expressão apesar de tudo, conforme (6) a (8). A Tabela 1 exibe as frequências absoluta e relativa dos padrões de pesar, em perspectiva longitudinal ${ }^{8}$.

(4) (...) só tinha o pesar de ser esta vinda em anno tão estéril $(20 \mathrm{OCH})$

(5) (...) me peza de vos ter offendido (20CNP)

(6) Apesar de todo o esforço até agora ainda não foi possível arranjar o dinheiro (20CFF)

(7) Os cozinheiros costumam fazer geléas animaes (...) Apesar de que essa geléa é mais agradável á vista, não é tão salutar como a que resulta do caldo de carne de vacca. (20CDC)

(8) o Conselheiro tinha, quando muito, 500 homens mal armados (...) posso ga-

\footnotetext{
${ }^{7}$ Foram excluídos desse cômputo os dados de em que pese, como em: É claro que, em que pese essa dificuldade, um imposto sobre fluxo de caixa minimiza as distorções (20RF) e os dados do verbo pesar, na acepção "determinar o peso": e os que mall pesarem ou medirem se o carneçeiro pessar per falsso pesso seja preso (15LRE).

${ }^{8}$ É possível observar a relevância da frequência relativa frente às diferenças da amostra textual. Por exemplo, os textos do século XV favoreceram muito mais ocorrências de pesar do que aqueles do século XVI, respectivamente, 159 e 52 dados. No entanto, os percentuais referentes aos padrões de pesar nesses períodos estão bastante próximos.
} 
rantir que aquelle mentecapto tem mais de cinco mil homens (...) Apesar de tudo, é urgente a liquidação de Canudos (20BM)

Tabela 1. Frequências absoluta e relativa dos padrões funcionais de pesar em perspectiva longitudinal

\begin{tabular}{|c|c|c|c|c|c|c|c|c|c|c|c|c|c|c|c|c|}
\hline & \multicolumn{2}{|c|}{ XIII } & \multicolumn{2}{|c|}{ XIV } & \multicolumn{2}{|c|}{$\mathbf{X V}$} & \multicolumn{2}{|c|}{$\mathbf{X V I}$} & \multicolumn{2}{|c|}{ XVII } & \multicolumn{2}{|c|}{ XVIII } & \multicolumn{2}{|c|}{ XIX } & \multicolumn{2}{|c|}{$\mathbf{X X} / \mathbf{X X I}$} \\
\hline & $\mathrm{N}$ & $\%$ & $\mathrm{~N}$ & $\%$ & $\mathrm{~N}$ & $\%$ & $\mathrm{~N}$ & $\%$ & $\mathrm{~N}$ & $\%$ & $\mathrm{~N}$ & $\%$ & $\mathrm{~N}$ & $\%$ & $\mathrm{~N}$ & $\%$ \\
\hline \multicolumn{17}{|l|}{ Padrões } \\
\hline pesar $_{\text {Nome }}$ & 24 & $73 \%$ & 64 & $69 \%$ & 97 & $61 \%$ & 28 & $54 \%$ & 23 & $41 \%$ & 19 & $40 \%$ & 27 & $18 \%$ & 25 & $11 \%$ \\
\hline pesar $_{\text {Verbo }}$ & 9 & $27 \%$ & 29 & $41 \%$ & 62 & $39 \%$ & 23 & $44 \%$ & 10 & $18 \%$ & 9 & $20 \%$ & 11 & $7 \%$ & 12 & $6 \%$ \\
\hline apesar de & & - & & - & & 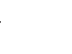 & 1 & $2 \%$ & 23 & $41 \%$ & 19 & $40 \%$ & 105 & $69 \%$ & 173 & $79 \%$ \\
\hline apesar (de) que & & - & & - & & 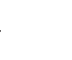 & & 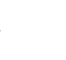 & & - & & - & 2 & $1 \%$ & 7 & $3 \%$ \\
\hline apesar de tudo & & - & & - & & . & & & & - & & - & 7 & $5 \%$ & 3 & $1 \%$ \\
\hline TOTAL & \multicolumn{2}{|c|}{$33100 \%$} & \multicolumn{2}{|c|}{$93100 \%$} & \multicolumn{2}{|c|}{$159100 \%$} & \multicolumn{2}{|c|}{$52100 \%$} & \multicolumn{2}{|c|}{$56100 \%$} & \multicolumn{2}{|c|}{$47100 \%$} & \multicolumn{2}{|c|}{$152100 \%$} & \multicolumn{2}{|c|}{$220100 \%$} \\
\hline
\end{tabular}

Fonte: Elaborado pela autora

A distribuição dos dados nos diferentes estados de língua permite verificar que, nos estágios mais antigos, século XIII a XV, foram apurados somente padrões lexicais, em contraste com os dados do português contemporâneo, em que temos alta frequência de padrão gramatical. Nos dados do século XVI, foi documentado o primeiro emprego da perífrase preposicional a pesar de, construção que se firmou, nos períodos subsequentes, como o padrão gramatical mais usado (79\% dos dados do séc. XX/XXI). Usos da perífrase a pesar (de) que, bem como da expressão a pesar de tudo, têm frequência menor e são de constituição mais recente, na amostra investigada. A coexistência entre padrões de uso de pesar antigos e inovadores, em um mesmo estado de língua, indicia gradiência sincrônica. Nas seções que seguem, o reconhecimento de estágios de mudança associados a contextos específicos fornecerá indícios de gradualidade diacrônica.

\subsection{Os três contextos semânticos}

Os dados de pesar foram classificados conforme o parâmetro semântico, em compatíveis com o significado fonte, compatíveis com ambos os significados fonte e alvo e compatíveis somente com o significado alvo e, em seguida, foram descritos em termos morfossintáticos. O Gráfico 1 mostra a evolução longitudinal dos padrões semânticos e sugere mudança em curso. Destaco que as linhas que representam fonte e alvo seguem direções contrárias, descendente para fonte e ascendente para alvo; e que a transição entre 
os séculos XVIII e XIX é o período em que, segundo o material de análise, há inversão nas frequências, com prevalência crescente do significado alvo (75\%), tendência que se mantém até os dados atuais. Casos de dupla interpretação têm pico entre os séculos XVI e XVII, coincidindo justamente com a curva ascendente dos contextos incompatíveis com o significado fonte. No que segue, discuto e exemplifico esses padrões de modo circunstanciado.

Gráfico 1. Padrões semânticos das construções com pesar em perspectiva longitudinal

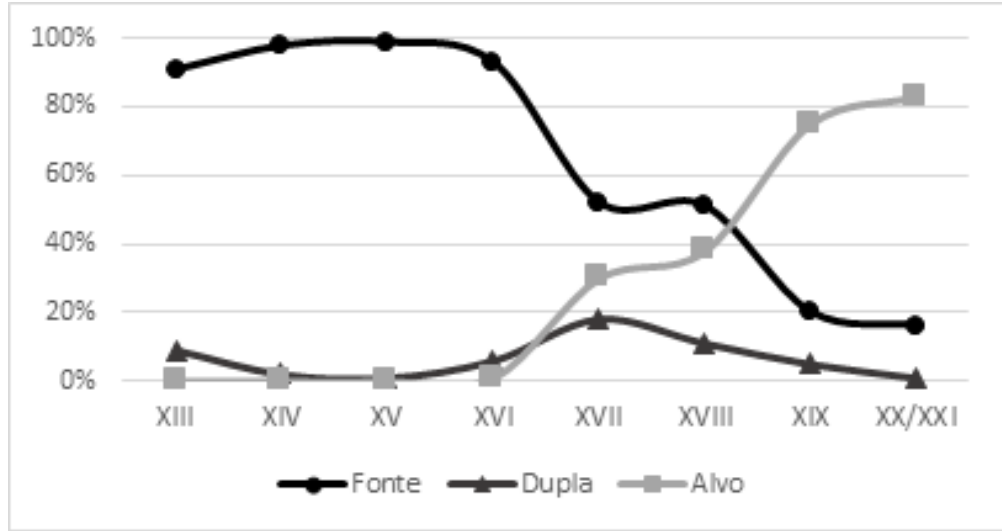

Fonte: Elaborado pela autora

i) Compatibilidade com o significado fonte. Nas ocorrências em que pesar é compatível com o significado fonte, ele é palavra lexical, verbo ou nome. Do ponto de vista etimológico, o verbo pesar, derivado do lat. pensāre ('suspender', 'por em balança'), assumiu no português arcaico o significado de 'tomar peso pendurando um corpo', 'ter um dado peso', mas também o significado mais abstrato de 'causar dor, tristeza, mágoa ou dó a alguém', caso em que frequentemente era impessoal, acompanhado de pronome dativo. Da substantivação do infinitivo resultou o nome pesar, com acepção de 'mágoa, dó, desgosto, tristeza' (MAGNE, 1944; MACHADO FILHO, 2013). Seguem exemplares dos padrões verbal e nominal de pesar encontrados na amostra:

(9) por vós, senhor, muyto mi pesará (13CAM)

(10) E a seu filho Enheguez Guerra pesava muito de sa prisom (14NL)

(11) Como el-rei fez seu doo por seus cavaleiros, e como lhe pesava de sa ida (15DSG)

(12) e pesou desto muito a elRei e aa Rainha sua madre e a outros muitos (15CDP) 
(13) Des que m' espertei, ouvi gran pesar (13CA)

(14) Eu ey pesar e coita por meu criado, que ora mort' achey (13CSM)

(15) Mais pero metestes-me mui gram pesar no meu coraçom (14NL)

(16) nenhuũ nõ uus poderya contar nen dizer o gran dóó nen o gran pesar que ouuerõ (14TSN)

(17) com mui gram pesar de que nom vinha aa corte (15DSG)

(18) Outrossi has de sofrer muyto frio e muyta fame e muytos pesares (14FS)

Como verbo, pesar expressava causar sofrimento a alguém ou, mais frequentemente, causar sofrimento a alguém de/por algo ou alguém, conforme (9)-(12). O infinitivo substantivado, espelhando traços da fonte verbal, expressava sofrimento, dor, angústia ${ }^{9}$, e podia aparecer antecedido por determinantes e modificadores e/ou sucedido por adjuntos ou por complementos, sintagmáticos ou oracionais, conforme (13)-(17). Como nome de gênero único, só admitia flexão em número, como em (18). Envolvia-se, com maior frequência, com determinados tipos de verbo (haver, fazer, ficar, sofrer, dizer, meter, tomar, viver, morrer, mostrar, matar) e podia ser regido por diferentes preposições ( $a$, con, de, por, en, sen).

Entendo o nome pesar como uma instância de shell noun (SCHMID, 2000), visto que combina os traços abstração e inespecificidade: equivale a uma entidade de terceira ordem e, em vários contextos, apresenta uma lacuna cuja saturação é necessária para uma comunicação bem sucedida. A classe dos shell nouns é diversa, distribuindo-se, segundo Schmid (2000), por seis tipos (factual, linguístico, mental, modal, evento, circunstancial) hierarquizados em subtipos. Pesar filia-se à classe dos nomes mentais, do subtipo estado psicológico, que reúne nomes que caracterizam atitudes e emoções como resultado do conhecimento dos fatos, de modo que implicam causalidade e factualidade. Os nomes de estado psicológico desdobram-se, por sua vez, nas subfamílias surpresa e medo, que abrigam estados emocionais relacionados, respectivamente, a fatos do passado e do futuro. Schmid caracteriza a subfamília surpresa a partir do cruzamento entre a polaridade positiva/negativa e a fonte da causalidade, conforme Esquema 1, no qual pesar figura como

\footnotetext{
9 A partir dos textos do século XVII, aparecem ocorrências do nome pêsame com sentido de condolência, provável fruto da reinterpretação entre a forma lexical e o clítico me: e authoridade, a dar o pezame da morte do pay (17CPV); para todos the darem o pezame de o naõ poderem ver ás escuras (17AF); queira acceitar meus sinceros pêsames (19CWL).
} 
membro de polaridade negativa, mostrando afinidade com o passado e com fontes causais diversas. Essa caraterização de pesar sugere, no viés da mudança, conexões entre fonte e alvo, já que os conceitos de negação e de causalidade, latentes ao nome pesar, integram o padrão de implicação das concessivas (Seção 1.1).

Esquema 1. Diferenciação semântica de nomes da subfamília Surpresa

\begin{tabular}{l|l|l}
\hline \multicolumn{1}{c|}{$\begin{array}{c}\text { Estado emocional } \\
\text { Causa }\end{array}$} & \multicolumn{1}{|c}{ Emoção positiva } & \multicolumn{1}{c}{ Emoção negativa } \\
\hline Qualquer tipo de fato & $\begin{array}{l}\text { deleite, gratidão, felicida- } \\
\text { de, } \\
\text { alegria, prazer, alívio, sa- } \\
\text { tisfação, emoção }\end{array}$ & $\begin{array}{l}\text { raiva, aborrecimento, amar- } \\
\text { gura, pesar, nojo, frustração, } \\
\text { fúria, tristeza, rancor, indig- } \\
\text { nação, dor, irritação, ressenti- } \\
\text { mento, raiva }\end{array}$ \\
\hline $\begin{array}{l}\text { Um fato para o qual o expe- } \\
\text { rien-ciador se sente respon- } \\
\text { sável }\end{array}$ & orgulho, satisfação & $\begin{array}{l}\text { preocupação, culpa, arrepen- } \\
\text { dimento }\end{array}$ \\
\hline
\end{tabular}

Fonte: Adaptado de Schmid (2000, p. 228).

Embora pesar tenha uma expressão semântica estável (mental>estado psicológico>surpresa), com traços inerentes de causalidade e de polaridade negativa, em certos contextos, ainda necessita de complementação, à maneira do verbo que lhe deu origem. Assim, a interpretação de pesar depende fundamentalmente de informações contextuais, como é típico dos shell nouns, e é justamente nos contextos que encontra condições para expansão de seu significado, como argumento a seguir.

ii) Dupla compatibilidade com os significados fonte e alvo. Tomo como instâncias de dupla interpretação as ocorrências em que, juntamente à semântica lexical de pesar, há possibilidade interpretativa em termos de alguma nuança de contraste, embora nem sempre na mesma intensidade. No corpus, há dois cenários diferentes. No primeiro, de que (19)-(25) são exemplares, o contexto de pesar apresenta indicação explícita do indivíduo que experiencia o sentimento de tristeza (i.e., genitivo possessivo), seja por meio de pronome (meu, seu), conforme (19), (20) e (24), seja por meio de sintagma preposicional (do emperador, d'el rei, de Mafoma, de minha mãe), conforme (21), (22), (23) e (25). $\mathrm{O}$ constituinte genitivo satura pesar, enquanto shell noun, e a construção sentencial implica causalidade: as ocorrências expressam fatos que têm por consequência o pesar de alguém. Assim, por exemplo, em (19), a partida de alguém é a causa ou motivo do pesar; em (21), a permanência do rei D. Fernando na França causa pesar ao imperador e ao rei 
da França; em (23), é a derrota dos mouros pelos portugueses que causa pesar a Mafoma (=Maomé); e, em (24), tomar madeira das costas é a causa do pesar. Em todos os casos, o significado fonte está em primeiro plano, e convive com uma inferência pragmática de desagrado, que decorre do fato, plausível nas sociedades humanas, de que tudo que se realiza com pesar se faz contra a vontade daquele que experimenta o pesar.

(19) Que mui gran torto mi fez, amiga/ meu amigo, quando se foi daqui/ a meu pesar, pois que lho defendi (13CA)

(20) ca servo a outren, non por mh o gracir, e que am'ela muyt'a sseu pesar (13CAM)

(21) E este Rui Diaz levou el rei dom Fernando de Castela, pera França, e esteve seis meses em França a pesar do emperador e d'el rei de França e de sete reis e do papa (14NL)

(22) Meestre de Santiago que tiinha a voz do conde dom Anrique, que esteve sempre em Lerena a pesar d'el rei, doze legoas de Sevilha, com mil e dozentos de cavalo, que nunca quis partir do reino. (14NL)

(23) Mas a pezar fentidiffimo de Mafoma, (...) em taõ renhidas batalhas, havendo em algnmas quafi cem Mouros contra cada hum fó Portuguez, ficaraõ fempre os Mouros inteiramente eftroçados, os feus Reys vergonhofamente vencidos, e fó Portugal gloriofamente triunfante (15CDA)

(24) me daram muyta madeyra nas coftas a meu pefar. (16TGV)

(25) Apa: Perdoayme vos fenhor. Efcu: Ora fizelte peor aa pefar de minha mãy. (16TGV)

Além disso, nos dados de (19)-(25), o contexto sintático mostra regularidades e é sugestivo de mudança em direção à perífrase: pesar é sempre regido pela preposição $a$ e, na ausência de pronome possessivo ( $m e u, s e u)$, um sintagma preposicional encabeçado por de, selecionando um referente humano, cumpre o papel de genitivo. Desse modo, esses dados fornecem indícios tanto da possível constituição de um novo significado, a partir da inferência de contra vontade de um sujeito, quanto da constituição gradiente de uma preposição complexa, a partir da ocorrência adjacente de dois sintagmas preposicio- 
nais, $a+$ pesar $+d e+$ nome.

No outro cenário de dupla interpretação, conforme (26)-(29), as construções também mostram contiguidade de dois sintagmas preposicionais e o constituinte selecionado por de continua sendo humano. A diferença é que a leitura de contra vontade parece evoluir para uma objeção, dado que um fato ou evento apresenta-se como uma dificuldade ou como um possível impedimento. São construções comuns em dados dos séculos XVII e XVIII. Em (26), por exemplo, são legítimas as duas leituras: a de que a passagem ao rio se realiza contra vontade ou para desgosto do inimigo, interpretação acessada ainda a partir das partes componentes; e a de que o próprio inimigo representa uma dificuldade à passagem pelo rio, interpretação menos composicional. Em (28), os fatos se referem à entrada dos cristãos e à tomada da mesquita. Nesse contexto, a expressão apesar dos mouros pode ser interpretada no sentido de que o evento provocou o descontentamento dos mouros ou que o evento se deu pela superação da dificuldade imposta pelos mouros. De fato, em todas as ocorrências, estão em questão 'dois grupos ou forças contrárias'. Nesse segundo conjunto de casos de dupla interpretação, diferentemente do primeiro (cf. (19)(25)), o significado fonte começa a se generalizar, tanto que a interpretação em termos de sofrimento é menos óbvia frente àquela de objeção.

(26) Aceftou em roda do Arrayal feis peças de artelharia, feis roqueiras, três falcoens de bróze, que tirou com algũas muniçoens de hũa náo Portugueza, que a pezar do inimigo entrou em hum rio da Bahya, por meyo de fua armada. (17JVC)

(27) hũa noite, que entrou de guarda fugio para o Castello de Airona com a sua companhia formada, officiais, armas, tambores, \& bandeiras, a pesar da caualleria Castelhana que hia no seu alcance. (17G)

(28) fobem os mininos pela ferra acima, vam entoãdo a sãta doutrina, enchem os valles as vozes defta innocente foldadefca; entram, a pezar dos Mouros, na mefquita, arvóra o Padre no mais alto della huma fermofa cruz, em final de victoria. (17CCJ)

(29) a mageftade do Rey dos Romanos Dõ Fernando (...) deo principio ao noffo Collegio, em Viena de Auftria, na alta Alemanha, a pezar dos hereges que contra nós ladravam, \& como inimigos da verdade guerreavam. (17CCJ) 
À luz das propriedades prototípicas de juntores, elencadas por Kortmann (1997), conforme Seção 1.1, casos de dupla interpretação como (26) a (29) aproximam-se do estatuto perifrástico, pois apresentam padrão sintático regular em a pesar de $S N_{\text {Hum }}$ posição à esquerda da unidade em que ocupam e pesar não se flexiona em número. A esse contexto estrutural estão vinculadas inferências pragmáticas, como descrevi acima, acrescidas ao significado codificado da fonte nominal, que ainda está presente. Com o uso repetido, ao longo do tempo, suponho que a sequência contígua $a+$ pesar + de ganhou em coesão formal e semântica (chunk) e passou a fazer parte das representações mentais, enriquecendo o repertório cognitivo dos usuários da língua. Como parte das representações, os conteúdos são reativados a cada nova situação comunicativa e, aos poucos, o que antes era apenas inferido, sustentado por correlatos contextuais, se torna parte do significado da construção. Na medida em que os significados se estabilizam no uso da língua, os usuários tendem a estendê-lo a novos ambientes sintáticos, como abordo em detalhe na Seção 3.2.

iii) Compatibilidade somente com o significado alvo. Nesse padrão estão as ocorrências de perífrases preposicional e conjuncional e da expressão apesar de tudo que estabelecem relações concessivas e bloqueiam o significado fonte. Há pelo menos dois tipos concessivos, que se prestam a uma avaliação em termos de maior ou menor subjetividade. Embora a quebra de expectativa seja o traço definidor comum às ocorrências, as bases da quebra de expectativa não são as mesmas. Assim, é possível distinguir casos em que a quebra de expectativa decorre de uma situação inesperada fruto da suspensão de uma relação causal, no plano do conteúdo sócio-físico, como em (30)-(32); e outros casos em que ela decorre de uma manobra argumentativa, no plano enunciativo, envolvendo objeções em diferentes níveis, como em (33)-(38). Ambos os tipos são reconhecidos na literatura (RUDOLPH, 1996; PANDER MAAT, 1999; LATOS, 2009) e aqui são denominados, respectivamente, concessão por causa negada e por restrição.

(30) fe recolheo cõ feu companheiro no hofpital de todos os Sanctos na cidade de Lisboa; aonde, a pezar da moleftia da quartaã, cõtinuou em feus fanctos exercicios, prègando, confeffando, ajudando aos enfermos (17CCJ)

(31) A Infantaria, que levava, eraõ quafi oytocentos homens, fora a marinhagem. Sahiraõ, \& a pezar de duas bravas tormentas, com que o inferno pretendia impedir a empreza, chegàraõ a Manffangano. (18HIM) 
(32) A pezar de todas as diligencias ainda até hoje nos não foi possível encontrar o manuscripto de Antônio Salema sobre a Conquista do Cabo Frio. (19TDB)

(33) Neste methodo ha a mesma perda de tempo, e quasi o mesmo gráo de fermentação, que no primeiro, a pezar de poder a água, em que estão as cerejas de molho no primeiro, e ultimo caso, dissolver alguma parte da gomma. (18OFB)

(34) Esperamos que o leitor nos desculpe a digressão que fizemos sobre esta palavra, acerca da qual desejávamos que se assentasse em uma orthographia. Apezar da preferencia que já a sciencia deu a aypi, nós em linguagem preferiríamos, com os clássicos Gandavo e Soares, aipim. (19TDB)

(35) (...) homem feito que, apezar de inapto para a carreira das lettras, possuia outras qualidades que poderiam ser úteis á poderosa Companhia de Jesus (19POI)

(36) Gallinhola do campo e de agua. Estas duas espécies de gallinholas preparam-se e servem-se como os patos, mas apesar de que com ellas se pode fazer uma grande variedade de entradas, a galinhola do campo serve-se a maior parte das vezes no espeto. (20CDC)

(37) (...) apesar de sua apparencea não mostrar acho-a bem doente (20CWL)

(38) (...) a communicação feita pelo Exm. Presidente da Bahia, datada de 1. de janeiro, de terem sido atacadas [pela febre amarela] para cima de vinte mil pessoas, e terem succumbido mais de cento e sessenta estrangeiros, pela maior parte marinheiros (...), apezar de tudo, descuidamo-nos, talvez porque vinham sempre noticias consoladoras de sua benignidade e da esperança de sua próxima extincção, ou porque nunca nos persuadimos que ella nos viesse assaltar (19DFA)

Os dados de (30) a (32) têm por base relações de causa ou motivo, no mundo real. Em (30), a moléstia é motivo suficiente para suspensão das atividades, no entanto, ela não tem efeito, pois o religioso dá continuidade aos ofícios. $\operatorname{Em}(31)$, as bravas tormentas constituem razão para o fracasso da empresa, mas foram superadas. Em (32), as diligências deveriam levar aos manuscritos, mas não tiveram sucesso. A suspensão das relações causais, nesses contextos, permite a inferência de que o que acontece é inesperado para 
a situação, portanto, quebra expectativas. Nesses dados, já não é possível recuperar a significado fonte, o que se deve, em parte, ao constituinte introduzido por de, que não tem mais o traço humano e se generalizou a diferentes tipos de entidades (cf. 3.2).

A outra fonte de quebra de expectativa nas concessivas com apesar está em formas de restrição argumentativa, em que o conteúdo da oração núcleo é retificado, restrito ou atenuado pelo conteúdo da concessiva, como (33)-(38). Nesse tipo concessivo, há sinalização de uma diferença entre forças argumentativas para legitimação de conclusões. A depender da ordenação das orações, ora as construções expressam uma antecipação de possíveis de objeções, como (34), (36) e (37), ora expressam ressalvas, como (33) e (35). Em (38), apesar de tudo retoma anaforicamente o conteúdo prévio, encapsulando-o, por meio de uma manobra argumentativa que conduz o leitor a acreditar que todas as objeções foram previamente ponderadas e refutadas para o acréscimo do argumento mais decisivo.

A frequência desses tipos de concessão, em perspectiva longitudinal, como mostra a Tabela 2, acrescenta um fato importante acerca da mudança. Nos dados, até o século XVIII, predomina a expressão de causalidade negada, ao passo que, nos séculos XIX e $\mathrm{XX} / \mathrm{XXI}$, a tendência se inverte, com grande prevalência das restritivas (70\%, no XX/ $\mathrm{XXI}$ ). Ambas as construções são fortemente subjetivas, já que lidam com suposições, como é típico da concessão, mas diferenciam-se no grau de subjetividade: o tipo causal atua no nível das relações sócio-físicas, entre o que acontece ou o que sefaz no mundo, e o restritivo, no nível das relações mentais, entre o que se pensa e enuncia.

Tabela 2. Tipo de significado concessivo nas construções compatíveis com alvo

\begin{tabular}{lcccccccccc}
\hline & \multicolumn{2}{c}{ XVI } & \multicolumn{2}{c}{ XVII } & \multicolumn{2}{c}{ XVIII } & \multicolumn{2}{c}{ XIX } & \multicolumn{2}{c}{ XX/XXI } \\
& $\mathrm{N}$ & $\%$ & $\mathrm{~N}$ & $\%$ & $\mathrm{~N}$ & $\%$ & $\mathrm{~N}$ & $\%$ & $\mathrm{~N}$ & $\%$ \\
Causalidade negada & 1 & $100 \%$ & 13 & $76 \%$ & 10 & $55 \%$ & 40 & $35 \%$ & 54 & $30 \%$ \\
Restrição & 0 & 0 & 4 & $24 \%$ & 8 & $45 \%$ & 74 & $65 \%$ & 129 & $70 \%$ \\
\hline TOTAL & 1 & $100 \%$ & 17 & $100 \%$ & 18 & $100 \%$ & 114 & $100 \%$ & 183 & $100 \%$ \\
\hline
\end{tabular}

Fonte: Elaborado pela autora

A Tabela 3 ilustra a frequência dos tipos concessivos segundo as possibilidades de ordenação do segmento concessivo - anteposição, posposição e intercalação - e sugere a existência de correlação. As construções de causa negada estão fortemente relacionadas à anteposição (86\%), já as restritivas se realizam com frequência considerável nas três posições, o que se explica em função da estratégia argumentativa em jogo, de antecipação ou de ressalva, como destaquei previamente. 
Tabela 3. Correlação entre tipo de concessiva e ordenação nas construções compatíveis com alvo

\begin{tabular}{ccccccc}
\hline \hline & \multicolumn{2}{c}{ Anteposição } & \multicolumn{2}{c}{ Posposição } & \multicolumn{2}{c}{ Intercalação } \\
& $\mathrm{N}$ & $\%$ & $\mathrm{~N}$ & $\%$ & $\mathrm{~N}$ & $\%$ \\
\cline { 2 - 7 } Causalidade negada & 101 & $86 \%$ & 16 & $13 \%$ & 1 & $<1 \%$ \\
Restrição & 79 & $37 \%$ & 92 & $43 \%$ & 44 & $20 \%$ \\
\hline \hline
\end{tabular}

Fonte: Elaborado pela autora

Os dados de apesar de e apesar (de) que compatíveis apenas com significado concessivo se conformam ao protótipo de juntor, fundado em Kortmann (1997), com a consolidação de várias propriedades. Por exemplo, a perda de composicionalidade é evidente a partir da ascensão do significado de quebra de expectativa, seja como produto de causa negada ou de restrição, e a descategorização do nome que, embora já viesse se processando nos casos de dupla interpretação, agora é mais evidente, na ausência de função sintática e de mecanismos flexionais, na inabilidade de receber determinantes e modificadores e na fixação da posição à esquerda. Quanto à propriedade da fusão, para dimensioná-la, lancei mão de três medidas, duas mais consistentes, que se referem à presença de material 'quebrando' a perífrase e à possível coordenação (BYBEE, 2010); e a terceira, de potencial mais restrito, relacionada à dimensão gráfica.

Para a presença de material interveniente, o resultado é altamente favorável ao estatuto de juntor complexo, visto que, em centenas de ocorrências, há apenas uma única com material, em (39). Quanto à coordenação, examinei a possibilidade de elipse de parte do sintagma, na expectativa de que o maior grau de fusão implique pouca ou nenhuma elipse, e investiguei a possibilidade de o juntor complexo se coordenar com outro juntor de valor similar. Os resultados apontam para o fato de que os segmentos encabeçados por apesar de são coordenados com $e$ ou por justaposição em 25 ocorrências. Nelas, há variação, conforme (40)-(41), com tendência maior à elipse, o que evidencia análises múltiplas e gradientes da perífrase, com fusão mais e menos frouxa. Identifiquei um dado em que apesar de é coordenado com outro juntor concessivo, como (42):

(39) Apezar, porém, dos esforços empregados pelo botânico Conceição Velloso com o fim de promover a cultura do cafeeiro, permaneceu este por muito tempo nos jardins do Rio de Janeiro. (19BC)

(40) (...) a pezar de produzirem as plantações feitas nos altos montes hum Café tão grande (...); e de fazerem os plantadores das mais partes da ilha (18OFB)

(41) (...) apesar do desejo que se pintava em todos os semblantes, apesar da impa- 
ciência de officiaes (20BM)

(42) A peça embora datada e apesar de suas ostensivas intenções polêmicas, está repleta de trouvailles (20ORV)

Por fim, ainda que a dimensão gráfica seja um índice de fusão bem menos confiável, por ser determinada em grande parte por convenções da escrita, no caso das construções com pesar, parece haver alguma relevância. A Tabela 4 apresenta os resultados da classificação dos dados de perífrases quanto à colocação ou não do espaço em branco entre $a$ e pesar. Nos dados dos séculos XVII e XVIII, embora a grafia mostre flutuação, a manutenção do espaço em branco é mais frequente (31\%, no XVIII); já nos dados do século XIX, esse resultado se inverte, com frequência maior de ausência do espaço (97\%) e, nos séculos XX/XXI, a escrita está padronizada, sem segmentação. Esses fatos permitem interpretar que a fusão gráfica entre $a$ e pesar é crescente no tempo e parece refletir, nas convenções da escrita, a consolidação das mudanças nos planos morfossintático e semântico.

Tabela 4. Fusão de $a+$ pesar no plano gráfico, em perspectiva longitudinal

\begin{tabular}{lcccccccccc}
\hline \hline & \multicolumn{2}{c}{ XVI } & \multicolumn{2}{c}{ XVII } & \multicolumn{2}{c}{ XVIII } & \multicolumn{2}{c}{ XIX } & \multicolumn{2}{c}{ XX/XXI } \\
& $\mathrm{N}$ & $\%$ & $\mathrm{~N}$ & $\%$ & $\mathrm{~N}$ & $\%$ & $\mathrm{~N}$ & $\%$ & $\mathrm{~N}$ & $\%$ \\
Com espaço em branco & 1 & $100 \%$ & 17 & $74 \%$ & 13 & $69 \%$ & 3 & $3 \%$ & 0 & 0 \\
Sem espaço em branco & 0 & 0 & 6 & $26 \%$ & 6 & $31 \%$ & 104 & $97 \%$ & 180 & $10 \%$ \\
\hline TOTAL & 1 & $100 \%$ & 23 & $100 \%$ & 19 & $100 \%$ & 107 & $100 \%$ & 180 & $100 \%$ \\
\hline \hline
\end{tabular}

Fonte: Elaborado pela autora

\subsection{Generalização sintático-semântica e a constituição de apesar de (que)}

Nesta subseção, em complementação à anterior, acrescento mais detalhes sobre os processos de generalização sintática e semântica. A Tabela 5 apresenta dados referentes à generalização sintática do constituinte selecionado pela perífrase apesar de. A princípio, nos dados dos séculos XVI e XVII, apesar de só selecionava nomes, muitos deles modificados por oração relativa, conforme (43)-(44). No material do século XVIII, embora a ocorrência de nomes seja a mais frequente $(63 \%)$, verifiquei casos em que a perífrase seleciona uma oração não finita, como em (45), uma estrutura com infinitivo flexionado que, ao articular explicitamente um sujeito e um predicado, aproxima a construção do domínio conjuncional. Ainda nesse período, identifiquei o primeiro dado com pronome demonstrativo neutro (isto), item de grande potencial anafórico encapsulador, conforme (46). Nos dados dos séculos XIX e XX/XXI, destaco a frequência crescente de orações não finitas, sobretudo no século XX/XXI (47\%), e as primeiras ocorrências de orações finitas, como em (47) e (48), que se realizam preferencialmente com indicativo. 
Tabela 5. Generalização sintática do constituinte selecionado por apesar de

\begin{tabular}{lcccccccccc}
\hline \hline & \multicolumn{2}{c}{ XVI } & \multicolumn{2}{c}{ XVII } & \multicolumn{2}{c}{ XVIII } & \multicolumn{2}{c}{ XIX } & \multicolumn{2}{c}{ XX/XXI } \\
& $\mathrm{N}$ & $\%$ & $\mathrm{~N}$ & $\%$ & $\mathrm{~N}$ & $\%$ & $\mathrm{~N}$ & $\%$ & $\mathrm{~N}$ & $\%$ \\
\hline a pesarde+ & & & & & & & & & & \\
SN & 1 & $100 \%$ & 23 & $100 \%$ & 12 & $63 \%$ & 61 & $57 \%$ & 78 & $43 \%$ \\
Or não Finita & - & - & - & - & 6 & $32 \%$ & 32 & $30 \%$ & 85 & $47 \%$ \\
Or Finita & - & - & - & - & - & - & 2 & $2 \%$ & 7 & $4 \%$ \\
Pro Anafórico & - & - & - & - & 1 & $5 \%$ & 12 & $11 \%$ & 10 & $6 \%$ \\
\hline TOTAL & 1 & $100 \%$ & 23 & $100 \%$ & 19 & $100 \%$ & 107 & $100 \%$ & 180 & $100 \%$ \\
\hline \hline
\end{tabular}

Fonte: Elaborado pela autora

(43) Mas o noffo Governador Fr. Manoel da Refurreiçaõ, eftá taõ teimofo em mandar partir a frota a pezar dos tempos, e dos mareantes (17CPV)

(44) Nefte mefmo anno, a petiçam do Cardeal de Lotharingia, entrou a Companhia em Paris, a pezar das grandes tempeftades que os hereges levantaram. (17CCJ)

(45) (...) elles se fazem dignos do Patroçínio de V.Sa. ahinda apezar de V. Sa. naõ ser correspondido como mereçe (18CPM)

(46) Se o nó mais distante tiver hum bom ramo secundário dever se ha tratar do modo, que se explanou no Num. XXXIX. Se o não tiver, deve-se a pezar disto deixar (18OFB)

(47) As obras antigas tem alguma beleza, tem mesmo belas formas, apezar que os taes narizes gregos nunca me cahiram em graça. (19EA)

(48) a USP que é a melhor universidade da América Latina e talvez seja uma das melhores do mundo... apesar que me disseram a pouco tempo que em uma pesquisa nós não estamos dentro das cem melhores (21LPF)

A generalização sintática experimentada pelo constituinte selecionado por de - de sintagma nominal a oração não finita e oração finita - se processa, até certo ponto, em paralelo à generalização dos significados, com enfraquecimento crescente da semântica lexical de pesar que impacta também a semântica do nome selecionado por de. Vimos na Seção 3.1 que, no período arcaico, quando o nome pesar selecionava nomes, em geral, eram nomes referenciais humanos e os contextos, tipicamente composicionais, como (49). Contudo, na medida em que o significado de pesar é enfraquecido em favor dos 
significados de contra vontade, objeção e quebra de expectativa, as possibilidades de seleção nominal também se expandem, conforme (50)-(52). Essa expansão parece se dar em três direções: a nomes que têm relação metonímica com humanos (indiferença, doente, repugnância, inveja, sofrimento, ingratidão); a nomes que designam entidades não humanas circunscritas em dimensões espaço-temporais (oceano, tormenta, chuvas, sinais, veneno, molho, peixe, tiros), e a nomes abstratos que designam situações ou eventos (desperdício, contrariedade, bloqueio). A generalização semântica de pesar é tal que a perífrase pode selecionar o nome pesares, como (53):

(49) Entam houve tam gram pesar de Lançarot (15DSG)

(50) (...) Apezar de tanta ingratidão o fundador do Instituto dos cegos continuou com a mesma dedicação. (19IMC)

(51) (...) grassavam com força em Mamanguape e outros lugarejos da província, apezar das chuvas (19DFA)

(52) Todavia é preciso confessar que, apezar de todas as contrariedades, a Instituição formou alguns alumnos distinctos. (19IMC)

(53) Lucinha, apesar dos pesares eu gosto muito de você (20CFF)

A Tabela 6, a seguir, apresenta as frequências que resultaram da classificação dos sintagmas nominais selecionados por apesar de conforme essas quatro categorias:

Tabela 6. Generalização semântica do sintagma nominal selecionado por apesar de

\begin{tabular}{|c|c|c|c|c|c|c|c|c|c|c|}
\hline & \multicolumn{2}{|c|}{ XVI } & \multicolumn{2}{|c|}{ XVII } & \multicolumn{2}{|c|}{ XVIII } & \multicolumn{2}{|c|}{ XIX } & \multicolumn{2}{|c|}{$\overline{\mathrm{XX} / \mathrm{XXI}}$} \\
\hline & $\mathrm{N}$ & $\%$ & $\mathrm{~N}$ & $\%$ & $\mathrm{~N}$ & $\%$ & $\mathrm{~N}$ & $\%$ & $\mathrm{~N}$ & $\%$ \\
\hline Entidade humana & - & - & 6 & $26 \%$ & 1 & $8 \%$ & 0 & - & 6 & $8 \%$ \\
\hline $\begin{array}{l}\text { Metonímia com hu- } \\
\text { mano }\end{array}$ & 1 & $100 \%$ & 10 & $44 \%$ & 2 & $17 \%$ & 28 & $46 \%$ & 27 & $35 \%$ \\
\hline Entidade não humana & - & - & 2 & $9 \%$ & 5 & $42 \%$ & 15 & $24 \%$ & 20 & $25 \%$ \\
\hline Entidade abstrata & - & - & 5 & $22 \%$ & 4 & $33 \%$ & 18 & $30 \%$ & 25 & $32 \%$ \\
\hline TOTAL & 1 & $100 \%$ & 23 & $100 \%$ & 12 & $100 \%$ & 61 & $100 \%$ & 78 & $100 \%$ \\
\hline
\end{tabular}

Fonte: Elaborado pela autora

As frequências sugerem que, até o século XVII, apesar de seleciona mais frequentemente entidades relacionadas direta ou associativamente a referentes humanos, herança 
da fonte nominal pesar, mas que as possibilidades se ampliam, a partir do século XVIII, com o aumento da frequência de entidades não humanas e entidades abstratas. Essa generalização semântica parece correlacionada à generalização sintática rumo à seleção de orações. A esse respeito, assumo a hipótese, reforçada em Barra Jover (2002), de que se uma preposição é capaz de selecionar nomes que comportam dimensões espaço-temporais e nomes abstratos, então ela tem potencial para selecionar toda uma proposição. Assim, parece não se tratar de coincidência o fato de que as primeiras ocorrências de seleção de oração não finita tenham sido verificadas justamente nos textos do século XVIII (cf. Tabela 5).

Esses fatos relacionados à generalização sintática e semântica somados àqueles descritos na Seção 3.1, acerca dos padrões de compatibilidade semântica, contribuem para a elaboração de um mapa cronológico dos estágios de mudança associados a contextos, como esboçado no Quadro 3:

Quadro 3: Mapa cronológico dos estágios de mudança

de pesar rumo ao juntor complexo

\begin{tabular}{|c|c|c|}
\hline FONTE & DUPLA COMPATIBILIDADE & ALVO \\
\hline $\begin{array}{c}\text { sofrimento } \\
\quad> \\
\downarrow\end{array}$ & $\begin{array}{c}\text { contra a vontade }>\text { > forças contrárias: } \\
\qquad \text { objeção }>>\quad \downarrow\end{array}$ & $\begin{array}{c}\text { quebra expectativa (causa, restrição) } \\
\downarrow\end{array}$ \\
\hline pesarN & $a($ poss $)$ pesar $($ de $) \quad$ a pesar de $S N$ & apesar de SN apesar de SN/OrInf/OrFin \\
\hline Séc. XIII >>.... & Séc. XVII >> ..... & Séc. XVII >> ... $\quad$ Séc. XIX >> ... \\
\hline
\end{tabular}

Fonte: Elaborado pela autora

\section{Considerações finais}

O estudo das construções com pesar, em via diacrônica, trouxe algum esclarecimento sobre a cronologia dos primeiros usos gramaticais, sobre os contextos motivadores e sobre aspectos de gradualidade e de ritmo da mudança. Trouxe também possíveis respostas às questões postuladas previamente. Sobre a primeira questão, é possível afirmar que o funcionamento de pesar como shell noun, abstrato e inespecífico, é um fato crucial sobre a tendência à mudança, já que tal funcionamento requer saturação segundo condições contextuais. Para pesar, a preposição de é que se especializa nessa saturação, selecionando a princípio nomes e, posteriormente, orações não finitas e finitas, e mobilizando uma estrutura favorável à reinterpretação como juntor complexo. Além disso, a semântica inerente ao nome pesar, fundada em polaridade negativa e causalidade (subfamília surpresa), juntamente com os enriquecimentos inferenciais, ajudam a entender a direção da mu- 
dança de significado rumo às relações concessivas, com crescente subjetivização, o que responde à segunda questão. Sobre a terceira questão, os dados sugerem que a generalização semântica e a expansão dos contextos sintáticos caminham juntas. Na medida em que o significado de tristeza se enfraquece em favor das novas leituras de contra vontade e objeção, o nome perde seus traços morfossintáticos e a sequência se torna uma única unidade, uma preposição complexa, que se generaliza na seleção de entidades nominais diversas e também de orações.

\section{Agradecimentos}

Agradeço o apoio financeiro da Fundação de Amparo à Pesquisa do Estado de São Paulo (Fapesp), processo 2019/18144-5, e do Conselho Nacional de Desenvolvimento Científico e Tecnológico (CNPq), processo 305901/2017-6.

\section{Referências}

BARRA-JOVER, M. Propiedades léxicas y evolución sintáctica. El desarrollo de los mecanismos de subordinación en español. A Coruña: Toxoutos, 2002.

BYBEE, J. Language, usage and cognition. Cambridge: Cambridge University Press, 2010. HAGÈGE, C. Les processus de grammaticalisation. In: HASPELMATH, M. et. al. (Ed.). Language typology and language universals. Berlin, New York: Walter Gruyter, 2001, p.1609-1623.

HARRIS,M.Concessive clausesinEnglish and Romance.In:HAIMAN,J.; THOMPSON, S. (Ed.) Clause combining in gramar and discourse. Amsterdam/Philadelphia: John Benjamins, 1988, p. 71-99.

HEINE, B.; KUTEVA, T. The genesis of grammar: a reconstruction. New York: Oxford University Press, 2007.

KÖNIG, E. On the history of concessive connectives in English: diachronic and synchronic evidence. Lingua, 66, p.1-19, 1985.

KORTMANN, B. Adverbial subordination: a typology and history of adverbial subordinators based on European languages. Berlin, New York: Mounton de Gruyter, 1997.

LANG, E. Adversative connectors on distinct levels of discourse. In: COUPERKUHLEN, E.; KORTMANN, B. (Ed.): Cause, condition, concession, contrast. Berlin: Mouton de Gruyter, 2000, p. 235-256.

LATOS, A. Concession on Different Levels of Linguistic Connection: Typology of Negated Causal Links. Newcastle Working Papers in Linguistics, vol. 15, p. 82-103, 2009.

LETOUBLON, F. Pourtant, cependant, quoique, bien que: dérivation des expressions de la concession, de la restriction et de l'opposition. Cahiers de linguistique française, 5, p. 85-110, 1983. 
MACHADO FILHO, A. V. Dicionário etimológico do português arcaico. Salvador: EDUFBA, 2013.

MAGNE, A. A Demanda do Santo Graal: Glossário. Rio de Janeiro: Imprensa Nacional, 1944.

MAURI, C.; RAMAT, A. G. The development of adversative connectives: stages and factors at play. Linguistics, v. 50, n. 2, p. 191-239, 2012.

MAURI, C.; AUWERA, J. Connectives. In: ALLAN, K.; JASZCZOLT, K. (Ed.) The Cambridge Handbook of Pragmatics. Cambridge: Cambridge University Press, 2012, p. 377-401.

MOESCHLER, L.; SPENGLER, N. La concession ou la refutation interdite: approches argumentative et conversationnelle. Cahiers de linguistique française, 4, p. 7-36, 1982.

MOESCHLER, J. Connecteurs, encodage conceptual et encodage procedural. Cahiers de Linguistique française, Genève, n. 24, p. 265-292, 2002.

PANDER MAAT, H. Two kinds of concessives and their inferential complexities. In: KNOTT, A. et al. (Ed.) Levels of representation in discourse. Edinburgh: Human Communication Centre, 1999, p. 45-54.

PAUL, H. Princípios Fundamentais da História da Língua. Lisboa: Fundação Calouste Gulbenkian, 1886.

PRANDI, M. The Building Blocks of Meaning: ideas for a philosophical grammar. Amsterdam, Philadelphia: John Benjamins Publishing Company, 2004.

RUDOLPH, E. Contrast: adversative and concessive relations and their expressions in English, German, Spanish, Portuguese on sentence and text level. Berlin: Walter de Gruyter, 1996.

SCHMID, H. English Abstract Nouns as Conceptual Shells: From Corpus to Cognition. Berlin: Mouton de Gruyter, 2000.

TORRES CACOULLOS, R.; SCHWENTER, S. Towards an operational notion of subjectification. In: COVER, R.T.; KIM, Y. (Ed.) Proceedings of the 31st Annual Meeting of the Berkeley Linguistics Society, 2005, p. 347-358.

TORRESCACOULLOS, R. Relative Frequencyin the Grammaticization of Collocations: nominal to concessive a pesar de. In: FACE, T.; KLEE, C. (Ed.) Selected Proceedings of the 8th Hispanic Linguistics Symposium. Somerville: Cascadilla Proceeding Project, 2006, p.37-49.

TRAUGOTT, E.; DASHER, R. Regularity in semantic change. Cambridge: Cambridge University Press, 2002. 